\title{
Application of the surgical Apgar score (SAS) to predict postoperative complication(s) in the patients with traumatic brain injury: Study of single center in Indonesia
}

\author{
Muhammad Z. Arifin ${ }^{1}$, Andi N. Sendjaja ${ }^{2}$, Ahmad Faried ${ }^{1 *}$ \\ ${ }^{1}$ Department of Neurosurgery, Faculty of Medicine, Universitas Padjadjaran, Dr. Hasan Sadikin Hospital, Bandung, West Java, \\ Indonesia; ${ }^{2}$ Department of Neurosurgery, BP Batam Hospital, Batam, Indonesia
}

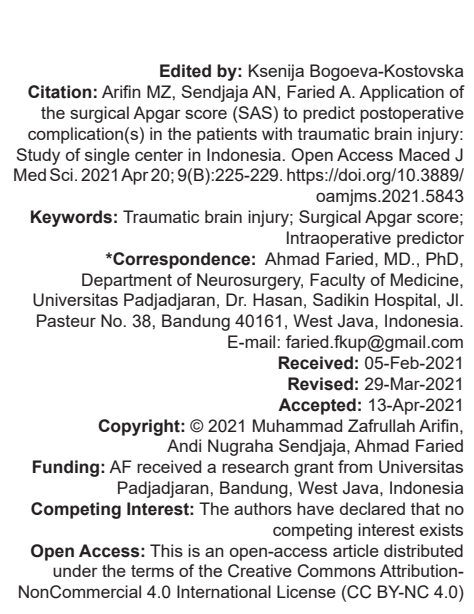

\section{Abstract}

BACKGROUND: Traumatic brain injury (TBI) is a major health problem. Surgery in patients with TBI is associated with a high rate of complications and mortality. The surgical Apgar score (SAS) is a simple quantitative and objective intraoperative tool for predicting major post-operative complications including mortality.

AIM: Our study aimed to analyze the use of SAS as a predictor of post-operative complications in patients with TBI.

METHODS: This was a prospective cohort study at our center in RSHS, Bandung, Indonesia, throughout 2017 by assessing SAS based on calculating intraoperative estimated blood loss, lowest mean arterial pressure, and lowest heart rate for each patient with TBI, as well as the incident complications within 30 days post-operative were recorded.

RESULTS: One hundred fifty-six patients with TBI underwent surgery in 2017 with 123 patients met the inclusion criteria. Among those, 63 patients $(51.2 \%)$ developed major complications with 8 patients $(12.7 \%)$ experienced death. The mean SAS for patients without complication was 8.20, whereas for patients with complication was 6.11 . SAS has an inverse correlation $(r=-0.754)$ and an association $(p<0.005)$ with post-operative complication (s) within 30 days.

CONCLUSIONS: The SAS has an inverse correlation and an association with incidence of complications thus potentially useful as an intraoperative predictor for incident complications within 30 days post-operative care in patients with TBI.

\section{Introduction}

Traumatic brain injury (TBI) is a major health problem, becoming a leading cause of death and disability in young adults worldwide. Globally, more than 1.2 million people die each year related to TBI. In Indonesia, road crashes are the sixth leading cause of the premature death [1]. The highest proportion of road traffic fatalities occurs in the younger age group of 15-29 years old, which makes up to $41 \%$ of the total 15,492 victims recorded in integrated road safety management system throughout 2016 [2]. The financial costs of road traffic crashes are estimated to be $2.9-3.1 \%$ of Indonesia's gross domestic product [3]. Although the number of reported crashes continued to drop in 2017, the number of road traffic deaths increased from 84 in 2016 to 157 in 2017. This represents a change in the road death rate from $3.4 / 100000$ people in 2016 to $6.3 / 100000$ in 2017. Motorcyclists contribute most of road injuries and deaths (69\% of deaths), with pedestrians as the second most affected group (23\% of deaths). Overall,
$93 \%$ of road deaths are among vulnerable road users (motorcyclists, bicyclists, and pedestrians). Road deaths occur mostly among men, $3 \times$ as many injuries and deaths than women, with the highest incidence in 15-24-year age group.

At Dr. Hasan Sadikin Hospital (RSHS), Bandung, from January 2012 to December 2017, there were 9006 cases of TBI with 6783 males $(75.32 \%)$ and 2223 females $(24.68 \%)$. The number of patients in each category (mild, moderate, and severe) was 5846 (64.91\%), 2111 (23.44\%), and 1049 (11.65\%), respectively, with 2444 cases $(27.15 \%)$ were indicated by intracranial hemorrhage lesions and 1105 cases $(12.27 \%)$ underwent surgery, with overall mortality occurring in 170 cases (1.88\%) [4]. Post-operative complications in neurosurgery provide a substantial contribution in increasing morbidity and mortality rates. In general, based on many studies, the post-operative complications dependent on the patient's condition. In the trauma centers, the patients with TBI tend to have the higher rates of post-operative complications compared to other medical facilities, this can be due to the number of emergency operative cases more than 
elective ones [5], [6]. In TBI, there are many scorings available as predictors of prognosis. The most common ones are pre-operative predictors such as the revised trauma score; the Glasgow coma scale (GCS), age and systolic blood pressure; and CRASH-scoring system [7], but there is no intraoperative predictors is available [8].

Gawande et al. in 2007 introduced an easy method for intraoperative assessment based on blood loss, heart rate, and blood pressure at the time of surgery to predict the occurrence of major complications within the 30 days post-operative known as the surgical Apgar score (SAS). SAS is useful in general- and vascularsurgery in reducing post-operative complication [9]. In 2009, Reynolds et al. conducted a study on the use of SAS in all surgical subspecialists in predicting postoperative mortality. This study showed that the surgery in trauma cases tends to have a low SAS and has a higher mortality rate versus to non-trauma surgery cases. Based on these studies, it was also concluded that SAS can be applied in various fields of surgery in providing predictions of mortality compared to complications [10] Ziewacz et al. in 2012 validated SAS for neurosurgical patients and concluded that SAS can predict mortality and complications such as increased treatment days in ICU and hospitalization [11]. Until now there is no consensus to evaluate intraoperative TBI cases in predicting the complications and mortality [12]. SAS in TBI case is expected to be a quantitative and objective measurement tool in reducing the occurrence of major complications after surgery [9], [10], [11], [12].

\section{Methods}

This was a single-institution prospective study at RSHS, Bandung, Indonesia. Patient data were collected from January 2017 to December 2017. The inclusion criteria were patients with TBI that underwent surgery for intracranial lesions. The intraoperative scoring was based on the amount of intraoperative bleeding, lowest heart rate, and lowest mean arterial pressure (MAP) at the time of surgery using 0-10 score system (Table 1). The exclusion criterion was patients of multiple traumas with abbreviated injury scale (AIS) $\geq 4$. Identified data were entered into Microsoft Excel 2010 and were analyzed using SPSS version 22.0 (Armonk, NY: IBM Corp., 2013) for Windows. The statistical differences considered significant when $p<0.05$.

Table 1: Surgical Apgar Score (SAS)

\begin{tabular}{llllll}
\hline & Score & & & & \\
\cline { 2 - 6 } & 0 & 1 & 2 & 3 & 4 \\
\hline Estimated blood loss $(\mathrm{cc})$ & $>1000$ & $601-1000$ & $101-600$ & $\leq 100$ & \\
Lowest MAP $(\mathrm{mmHg})$ & $<40$ & $40-54$ & $55-69$ & $\geq 70$ & \\
Lowest heart rate $(/$ minute) & $>85^{*}$ & $76-85$ & $66-75$ & $56-65$ & $\leq 55$ \\
\hline
\end{tabular}

\section{Results}

\section{The characteristics of the subjects}

As many as 1054 patients with $\mathrm{TBI}$ in the Department of Neurosurgery, RSHS, Bandung, were enrolled in this study within the period of January 2017-December 2017. Of these patients, 156 patients underwent surgery; however, 33 patients met the exclusion criteria. The exclusion criteria were as follows: Child patients, multiple traumas with AIS 14, and patients who were not admitted or voluntarily discharged and unavailability of the head computed tomography scan data. The characteristics of the subjects (Table 2) were in accordance with their age, gender, GCS pre-operative, severity of TBI, diagnosis pre-operative, and operative procedure. The mean age was $31.31 \pm 16.42$ years. There were 93 male patients $(75.6 \%)$ and 30 female patients $(24.4 \%)$. Mean of GCS pre-operative was $11.67 \pm 2.78$.

Table 2: The characteristics of the subjects

\begin{tabular}{ll}
\hline Variables & $\mathbf{N}=\mathbf{1 2 3}$ \\
\hline Age (Years Old) & \\
Mean \pm SD & $31.31 \pm 6.42$ \\
Median & 24 \\
Range (min-max) & $14-82$ \\
Gander & \\
$\quad$ Man & $93(75.6 \%)$ \\
Woman & $30(24.4 \%)$ \\
GCS preoperative & $11.67 \pm 2.777$ \\
Mean \pm SD & 12 \\
Median & $4-15$ \\
Range (min-max) & \\
Severity of Head Injury & $40(32.5 \%)$ \\
Mild & $74(60.2 \%)$ \\
Moderate & $9(7.3 \%)$ \\
Severe & \\
Diagnosis Preoperative & $53(43.1 \%)$ \\
Epidural Hemorrhage & $33(26.8 \%)$ \\
Depress Fracture & $21(17.1 \%)$ \\
Subdural Hemorrhage & $15(12.2 \%)$ \\
Intracerebral Hemorrhage & $1(0.8 \%)$ \\
Penetrate Injury & \\
Operative Procedure & $61(49.6 \%)$ \\
Craniotomy evacuation & $34(27.6 \%)$ \\
Craniectomy decompression & $28(22.8 \%)$ \\
Debridement & \\
\hline SD, Standard Deviation &
\end{tabular}

\section{Complication(s) after surgery}

One hundred twenty-three patients with TBI underwent surgery, complication(s) occurred in 63 patients $(51.2 \%)$ while in 60 other cases $(48.8 \%)$ the complication did not occur. The complications were observed as follows: Neurological deficit occurred in 61 cases $(96.8 \%)$, ventilator usage $>48 \mathrm{~h}$ occurred in $32(50.8 \%)$, coma $>24 \mathrm{~h}$ occurred in $24(38.1 \%)$, transfusion $>4$ units in $78 \mathrm{~h}$ occurred in $2(3.2 \%)$, wound dehiscence occurred in 6 (9.5\%), acute kidney injury occurred in 1 (1.6\%), pneumonia occurred in 35 $(55.5 \%)$, seizures occurred in $8(12.7 \%)$, sepsis or shock septic occurred in 4 (6.3\%), cardiac arrest occurred in 8 $(12.7 \%)$, re-intubation occurred in $4(6.3 \%)$, re-operation occurred in $1(1.6 \%)$, and death occurred in 8 cases $(12.7 \%)$. Based on the number of complication(s) in 1 case; patients who experienced 1 complication 
were 20 (31.7\%), 2 complications were $12(19.0 \%), 3$ complications were $8(12.7 \%), 4$ complications were 11 (17.5\%), 5 complications in $3(4.8 \%), 6$ complications in $3(4.8 \%), 7$ complications in $4(6.3 \%)$, and 9 and 11 complications in 1 case $(1.6 \%)$, respectively, none experienced 8 and 10 complications (Table 3).

Table 3: Postoperative Complication (s) on TBI Cases

\begin{tabular}{ll}
\hline Variables & Patients \\
\hline Postoperative Complication (s) & $\mathrm{N}=123$ \\
Yes & $63(51.2 \%)$ \\
No & $60(48.8 \%)$ \\
Type of Complication (s) & $\mathrm{N}=63$ \\
Neurology Deficit & $61(96.8 \%)$ \\
Pneumonia & $35(55.5 \%)$ \\
Ventilator Usage>48 hours & $32(50.8 \%)$ \\
Coma>24 hours & $24(38.1 \%)$ \\
Seizures & $8(12.7 \%)$ \\
Cardiac Arrest & $8(12.7 \%)$ \\
Death & $8(12.7 \%)$ \\
Wound Dehiscence (Infection) & $6(9.5 \%)$ \\
Sepsis/Shock septic & $4(6.3 \%)$ \\
Re-intubation & $4(6.3 \%)$ \\
Transfusion>4 unit in 78 hours & $2(3.2 \%)$ \\
Acute Kidney Injury & $1(1.6 \%)$ \\
Re-operation & $1(1.6 \%)$ \\
Number of Complication (s) in 1 patient & $\mathrm{N}=63$ \\
1 Complication & $20(31.7 \%)$ \\
2 Complications & $12(19.0 \%)$ \\
3 Complications & $8(12.7 \%)$ \\
4 Complications & $11(17.5 \%)$ \\
5 Complications & $3(4.8 \%)$ \\
6 Complications & $3(4.8 \%)$ \\
7 Complications & $4(6.3 \%)$ \\
8 Complications & $0(0 \%)$ \\
9 Complications & $1(1.6 \%)$ \\
10 Complications & $0(0 \%)$ \\
11 Complications & $1(1.6 \%)$ \\
\hline
\end{tabular}

\section{SAS profile intraoperatively on post- operative complication(s)}

Intraoperative variables were assessed using SAS based on the amount of bleeding, lowest-MAP and -heart rate during surgery. The mean intraoperative bleeding in the patients with complications was 639.65 $\pm 363.06 \mathrm{cc}$, while the average bleeding in patients without complications was $446.00 \pm 232.41 \mathrm{cc}$. The lowest intraoperative MAP in patients with complications was $61.97 \pm 9.51 \mathrm{mmHg}$, while the lowest MAP in the patients without complication was $69.48 \pm 5.34 \mathrm{mmHg}$. The lowest mean intraoperative heart rate in patients with complications group was 63.98 w $6.94 \times$ per min, while the mean lowest heart rate in the patients without complication was $58.68 \pm 7.28 \times$ per min. The above intraoperative profile was tested with an unpaired t-test; $p<0.05$, which means significant or has a statistically significant correlation; thus, it can be explained that there are significant differences between SAS variables in the complications group and no complication group (Table 4).

\section{SAS distribution on number(s) of post- operative complication(s)}

SAS values are obtained based on the intraoperative bleeding (consist of 4 assessment points, i.e., point 0 for bleeding $>1000 \mathrm{cc}$, point 1 for bleeding $601-1000 \mathrm{cc}$, point 2 for bleeding 101-600 cc,
Table 4: SAS Profile Intraoperative on Postoperative Complication (s)

\begin{tabular}{|c|c|c|c|}
\hline \multirow{3}{*}{ Variables } & \multicolumn{2}{|l|}{ Groups } & \multirow{3}{*}{$p$-Value } \\
\hline & Complication (s) & No Complication (s) & \\
\hline & $N=63$ & $\mathrm{~N}=60$ & \\
\hline Estimated blood loss (cc) & & & $0.000^{\star \star}$ \\
\hline Mean \pm SD & $639.65 \pm 363.06$ & $446.00 \pm 232.41$ & \\
\hline Median & 650 & 300 & \\
\hline Range (min-max) & $200-2000$ & $75-1100$ & \\
\hline Lowest MAP (mmHg) & & & $0.000^{* \star}$ \\
\hline Mean \pm SD & $61.97 \pm 9.51$ & $69.48 \pm 5.34$ & \\
\hline Median & 61 & 70.00 & \\
\hline Range (min-max) & $39-90$ & $55-80$ & \\
\hline Lowest heart rate (/min) & & & $0.000^{* *}$ \\
\hline Mean \pm SD & $63.98 \pm 6.943$ & $58.68 \pm 7.282$ & \\
\hline Median & 63 & & \\
\hline Range (min-max) & $50-81$ & $50-80$ & \\
\hline
\end{tabular}

and point 3 for bleeding $<100 \mathrm{cc}$; the lowest MAP value (consist of 4 assessment points, i.e., 0 for the lowest MAP $<40$, point 1 for lowest MAP 40-54, point 2 for lowest MAP 55-69, and point 3 for lowest MAP >70; lowest intraoperative heart rate (consist of 5 points, i.e., point 0 for the lowest heart rate $>859$ per min, point 1 for the lowest heart rate $76-85$ per min, point 2 for the lowest heart rate 66-75 5 per min, point 3 for the lowest heart rate $56-655$ per min, and point 4 for the lowest heart rate $<55$ per $\mathrm{min}$ ). These 3 points are added together to obtain the SAS score with the lowestand highest-value which is 0 and 10 , respectively. For the SAS $0-2$, one patient experiencing complications $(100 \%)$; for SAS $3-4$, eight patients $(100 \%)$; for SAS $5-6,28$ patients $(80 \%)$ had complications while 7 patients $(20 \%)$ did not; for SAS 7-8, 22 patients (44.9\%) had complications while 27 patients $(45.1 \%)$ did not; and for SAS 9-10, 4 patients (13.3\%) had complications while 26 patients $(87.7 \%)$ did not. The average of SAS in the complication(s) group was 6.11 \pm 1.525 while in no complication(s) group it was $8.20 \pm$ $1.246 \mathrm{cc}$. The median SAS in the complication(s) group was 6 (range 1-9), while no complication(s) group was 8 (range 5-10). For the analysis of intraoperative profiles to determine the correlation between SAS and the incidence of complications, the Gamma test was performed because the requirements were met (categorical data scale and correlative hypothesis). Correlative statistical test results obtained $r=-0.799$ and $p \leq 0.05$, thus SAS statistically has a strong correlation (0.75-0.99) with the occurrence of complications within 30 days post-operative. A negative result on this $r$ value can be concluded to have an inverse relationship; the higher the SAS, the number of post-operative complications was decreased ( $p \leq 0.05$ ), as shown in Table 5. The number of complications was divided into three (no complication, 1-3 complications, and $>3$ complications). Patients SAS $0-2$ had 1 patient with $>3$ complications. Patients SAS $3-4$ had 1 patient with 1-3 complications and 7 patients with $>3$ complications. Patients SAS 5 had 7 patients without complication, 19 patients with 1-3 complications, and 9 patients with $>3$ complications. Patients SAS $7-8$ had 27 patients without complications, 17 patients with 1-3 complications, and 5 patients with $>3$ complications. Patients SAS 9-10 had 26 patients without complication, 3 patients with 
1-3 complications, and 1 patient with $>3$ complications. The analysis of intraoperative profiles to determine the correlation between SAS and the number(s) of complication(s) performed by the Gamma test obtained $r=-0.754$ and $p \leq 0.05$ as a result, thus the SAS statistically has a strong correlation (0.75-0.99) with the number(s) of complication(s) within 30 days after surgery. A negative result on this $r$ value can be concluded to have an inverse correlation; the higher SAS value, the number(s) of complication(s) decreased postoperatively ( $p \leq 0.05)$, as shown in Table 6 .

Table 5: SAS Distributions on Postoperative Complication (s)

\begin{tabular}{|c|c|c|c|c|c|}
\hline \multirow[t]{3}{*}{ Variables } & \multicolumn{3}{|c|}{ Complication (s) } & \multirow[t]{3}{*}{$r$-value } & \multirow[t]{3}{*}{$p$-value } \\
\hline & No & Yes & Total & & \\
\hline & $\mathrm{N}=60$ & $\mathrm{~N}=63$ & $\mathrm{~N}=123$ & & \\
\hline SAS & & & & -0.799 & $0.000^{*}$ \\
\hline $0-2$ & $0(0 \%)$ & $1(100 \%)$ & 1 & & \\
\hline $3-4$ & $0(0 \%)$ & $8(100 \%)$ & 8 & & \\
\hline $5-6$ & $7(20 \%)$ & $28(80 \%)$ & 35 & & \\
\hline $7-8$ & $27(55.1 \%)$ & $22(44.9 \%)$ & 49 & & \\
\hline $9-10$ & $26(86.7 \%)$ & $4(13.3 \%)$ & 30 & & \\
\hline Mean \pm SD & $8.20 \pm 1.246$ & $6.11 \pm 1.525$ & $7.13 \pm 1.741$ & & $0.000^{*}$ \\
\hline Median & 8.00 & 6.00 & 7.00 & & \\
\hline Range (min-max) & $5-10$ & $1-9$ & $1-10$ & & \\
\hline
\end{tabular}

Table 6: SAS Distribution on Number (s) of Postoperative Complication (s)

\begin{tabular}{|c|c|c|c|c|c|c|}
\hline \multirow{3}{*}{ Variable } & \multicolumn{4}{|c|}{ Number (s) of Postoperative Complication (s) } & \multirow{3}{*}{$r$-value } & \multirow[t]{3}{*}{$p$-value } \\
\hline & 0 & $1-3$ & $>3$ & Total & & \\
\hline & $\mathrm{N}=60$ & $\mathrm{~N}=40$ & $\mathrm{~N}=23$ & $\mathrm{~N}=123$ & & \\
\hline$\overline{\text { SAS }}$ & & & & & -0.754 & $0.000^{*}$ \\
\hline $0-2$ & 0 & 0 & 1 & 1 & & \\
\hline 3-4 & 0 & 1 & 7 & 8 & & \\
\hline $5-6$ & 7 & 19 & 9 & 35 & & \\
\hline $7-8$ & 27 & 17 & 5 & 49 & & \\
\hline $9-10$ & 26 & 3 & 1 & 30 & & \\
\hline
\end{tabular}

\section{Discussion}

Bandung, West Java, Indonesia, is the nation's third most populous city with almost 2.5 million people in 2017 and 1617022 registered vehicles (65.840 vehicles per 100000 population). The highest injury and death rates are both among 15-24 years old at 38.6 per 100000 population for injury rates; 10.2 per 100000 population for death rates [13]. This fact is in agreement with our previous study that showed mostly from the younger population that were included to those rates, with a mean age of $32.28 \pm 19.097$. They were more likely to be male (88.0\%); $25.9 \%$ that had severe TBI (as defined by GCS and pupil reactivity) and they more often had abnormal results on computed tomography (CT) scan. Road traffic crashes were a more common cause of TBI [7].

\section{The aim of this study}

The aim of this study was to determine the usefulness of the SAS in predicting the incidence of post-operative complication(s) in TBI cases. Craniotomy is the most common procedures in in TBI cases at our center and several previous studies have shown that SAS has a significant correlation with morbidity and mortality [10], [11]. Of 123 patients, as many as 63 patients $(51.2 \%)$ experienced complications. The number of complications after neurosurgery especially in trauma cases is still relatively high. Rolston et al. (2014) reported the incidence of post-operative neurosurgical complications in the USA of $14.3 \%$, while Yousufali et al. (2016) reported the incidence of post-operative complications in TBI cases in Kenya by $56 \%$ [14], [15].

Complications after surgery are still common, especially in cases of neurotrauma such as craniotomy. The incidence of complication(s) in our study was $51.2 \%$ with mortality rate of $6.5 \%$ or occurred in 8 patients. This result was not much different from the rate of complications in the Ziewacz et al., who conducted a validation study in the entire population of neurosurgery cases, namely the complication(s) incidence rate was $15.8 \%$ and mortality rate was $2.6 \%$; complication(s) incidence rate for emergency cases was $43.7 \%$, and the incidence rate of complication(s) for trauma cases was $51.1 \%$. In line with Yousufali et al. who conducted studies on neurosurgical trauma cases, the incidence of complication(s) was $56 \%$ and mortality rates were $6 \%$. It was shown that surgery in trauma cases tends to have a higher mortality rate versus non-trauma. Mortality rate is used as mark for surgery outcome, but complications are a factor that influences morbidity and mortality rates post-operative [5], [10], [11], [15].

Since SAS was first introduced by Gawande et al. in 2007 several validations from various fields have been carried out and in particular neurosurgery as a predictor of post-operative complication(s). This assessment is an intraoperative assessment that can be used to predict post-operative complications [9], [10], [11], [12]. In this study, the median SAS in TBI surgery cases in our center was 7 with a mean value of $7.13 \pm 1.741$. Patients who experienced post-operative complication(s) had a median value of SAS 6 and mean value of $6.11 \pm 1.525$, while patients who did not experience complication(s) had a median value of SAS 8 and mean value of $8.2 \pm 1.246$. This showed that patients with the low SAS tend to experience complication(s) compared to patients with higher SAS ( $p<0.005$ ). It can be concluded that the intraoperative SAS assessment is associated with the incidence of post-operative complications and can be used as a predictor of TBI post-operative complications. Therefore, the SAS is useful as an intraoperative predictor for post-operative complication(s) and is very useful for prognosis and management especially in limited neurosurgery facilities. 


\section{Conclusions}

There was a strong inversely and statistically significant correlation between the SAS with incidence of complication(s) 30 days postoperatively in TBI cases; the lower SAS predicted the higher 30 day complication(s). The SAS scoring system can be used as intraoperative predictor of complication(s) occurring 30 days post-operative in TBI cases.

\section{Ethical Statement}

This study was approved by Faculty of Medicine, Universitas Padjadjaran ethics committee and has been performed in according ethical standards laid down Helsinki Declaration 1964.

\section{Authors' Contributions}

All authors had examined, treated, observed, and follow-up the patients. All authors participated in writing the manuscript, had read, and approved the final manuscript.

\section{References}

1. Institute of Health Metrics and Evaluation (IHME). Global Burden of Disease Report; 2016. Available from: http://www.healthdata. org/indonesia. [Last accessed on $2021 \mathrm{Mar}$ 03]

2. Korlantas Polri. Statistik Kecelakaan Lalu Lintas Jalan di Indonesia Tahun 2016. (Road Traffic Accident Statistics in Indonesia in 2016) Jakarta. Available from: http://www. korlantas.polri.go.id. [Last accessed on 2018 Jul 25]. https://doi. org/10.19184/korlantas-jirs.v1i1.14771

3. Government of the Republic of Indonesian. Rencana Umum Nasional Keselamatan Jalan (RUNK) 2010. (National Road Safety Plan 2010). Available from: http://www.perpustakaan. bappenas.go.id//ontar/file?file=digital/117404-[Konten]Konten\%20C7887.pdf. [Last accessed on 2021 Mar 03]

4. Faried A, Halim D, Widjaya IA, Badri RF, Sulaiman SF, Arifin MZ. Correlation between the skull base fracture and the incidence of intracranial hemorrhage in patients with traumatic brain injury. Chin J Traumatol. 2019;22(5):286-9. https://doi.org/10.1016/j.cjtee.2019.05.006 PMid:31521457

5. Hammers R, Anzalone S, Sinacore J, Origitano TC. Neurosurgical mortality rates: what variables affect mortality within a single institution and within a national database? J Neurosurg. 2010;112(2):257-64. https://doi.org/10.3171/2009.6.jns081235 PMid:19645537

6. Vedin $T$, Edelhamre $M$, Karlsson $M$, Bergenheim $M$, Larsson PA. Management of traumatic brain injury in the emergency department: Guideline adherence and patient safety. Qual Manag Health Care 2017:26(4):1905. $\quad$ https://doi.org/10.1097/qmh.0000000000000151 PMid:28991814

7. Faried A, Satriawan FC, Arifin MZ. Feasibility of online traumatic brain injury prognostic corticosteroids randomisation after significant head injury (CRASH) model as a predictor of mortality. World Neurosurg. 2018;116:e239-45. https://doi.org/10.1016/j.wneu.2018.04.180 PMid:29730104

8. Kondo $\mathrm{Y}$, Abe T, Kohshi K, Tokuda Y, Cook EF, Kukita I Revised trauma scoring system to predict in-hospital mortality in the emergency department: Glasgow coma scale, age, and systolic blood pressure score. Crit Care. 2011;15(4):R191. PMid:21831280

9. Gawande AA, Kwaan MR, Regenbogen SE, Lipsitz SA, Zinner MJ. An Apgar score for surgery. J Am Coll Surg. 2007;204(2):201-8. https://doi.org/10.1186/cc10348 PMid: 17254923

10. Reynolds PQ, Sanders NW, Schildcrout JS, Mercaldo ND, St Jacques PJ. Expansion of the surgical Apgar score across all surgical subspecialties as a means to predict postoperative mortality. Anesthesiology. 2011;114(6):130512. https://doi.org/10.1097/aln.0b013e318219d734 PMid:21502856

11. Ziewacz JE, Davis MC, Lau D, El-Sayed AM, Regenbogen SE, Sullivan SE, et al. Validation of the surgical Apgar score in a neurosurgical patient population. J Neurosurg. 2013;118(2):270-9. https://doi.org/10.3171/2012.10.jns12436 PMid:23121434

12. Greenberg CC, Roth EM, Sheridan TB, Gandhi TK, Gustafson ML, Zinner MJ, et al. Making the operating room of the future safer. Am Surg. 2006;72(11):1102-8; discussion 1126-48. $\quad$ https://doi.org/10.1177/000313480607201121 PMid:17120955

13. Johns Hopkins International Injury Research Unit and Universitas Padjajaran. Bandung: Data Technical Report-Round 6, Bloomberg Initiative for Global Road Safety; 2017.

14. Rolston JD, Han SJ, Lau CY, Berger MS, Parsa AT. Frequency and predictors of complications in neurological surgery: National trends from 2006 to 2011. J Neurosurg. 2014;120(3):736-45. https://doi.org/10.3171/2013.10.jns122419 PMid:24266542

15. Yusufali TS, Awori M, Ojuka KD, Wekesa VD. Surgical Apgar score predicts post-operative complications in traumatic brain injury. Ann Afr Surg. 2016;13(1):15-9. 